\section{Always fighting and keeping hope: my experience of a complete quadriceps rupture and multiligament knee injury}

\author{
Johan Rodriguez
}

\section{THE ACCIDENT}

Monday, 18 May 2020 around 17:00

I wake up in the intensive care unit of Saint-Etienne University Hospital, having been plunged into a coma for several hours. The day before, I was the victim of a road traffic accident, hit by a car while on my road bike.

I am Johan Rodriguez, a professional triathlete with Chambéry Triathlon (France) (figure 1). My team and I reached highest national level, which enabled us to compete with the best French and world triathletes.

The injuries sustained in my accident required emergency surgery to save my life, due to the massive bleeding I sustained. Dr Thomas Neri, my surgeon, visited me and was delighted to see me awake given the severity of the accident, which could have been fatal. The rare combination of injuries was very serious: a complete rupture of the four quadriceps heads at the myotendinous junction and a multiligament knee injury (the lateral collateral ligament and the popliteal tendon). In addition, I sustained a fracture of my clavicle and the scapula, and an open fracture of my metacarpal. The quadriceps rupture and the open hand fracture were operated on during my first emergency surgery.

\section{THE PROGNOSIS}

After the accident, I was very upset and angry. My functional prognosis was very uncertain, and my return to competition seemed almost impossible. Doctors told me that I would never return to my sporting life and that I should move on with other plans I had in mind. Alongside my physical pain, this threat to my identity came as a painful shock.

Despite this very pessimistic prognostic, I decided to prove those who doubted my healing capabilities wrong. As a way to stay positive and have something to hold on to, I decided from my hospital bed that I would return to triathlon competitions, win races and become stronger than before.

At that moment, pain and doubt were everywhere. My medical team were not

Chambéry Triathlon, Saint Chamond, France very optimistic, including my surgeon who at first did not give me much hope of returning to competition. Looking back, he had no choice but to be realistic. However, this sincerity boosted me as much as it irritated me. He had laid down a challenge to me, without intending to. His speech could have affected me like the accident had scalped my thigh, but I wanted to fight even harder.

\section{MY REHABILITATION}

Before knee surgery

This first part was the most complicated for my medical team. The recovery of my

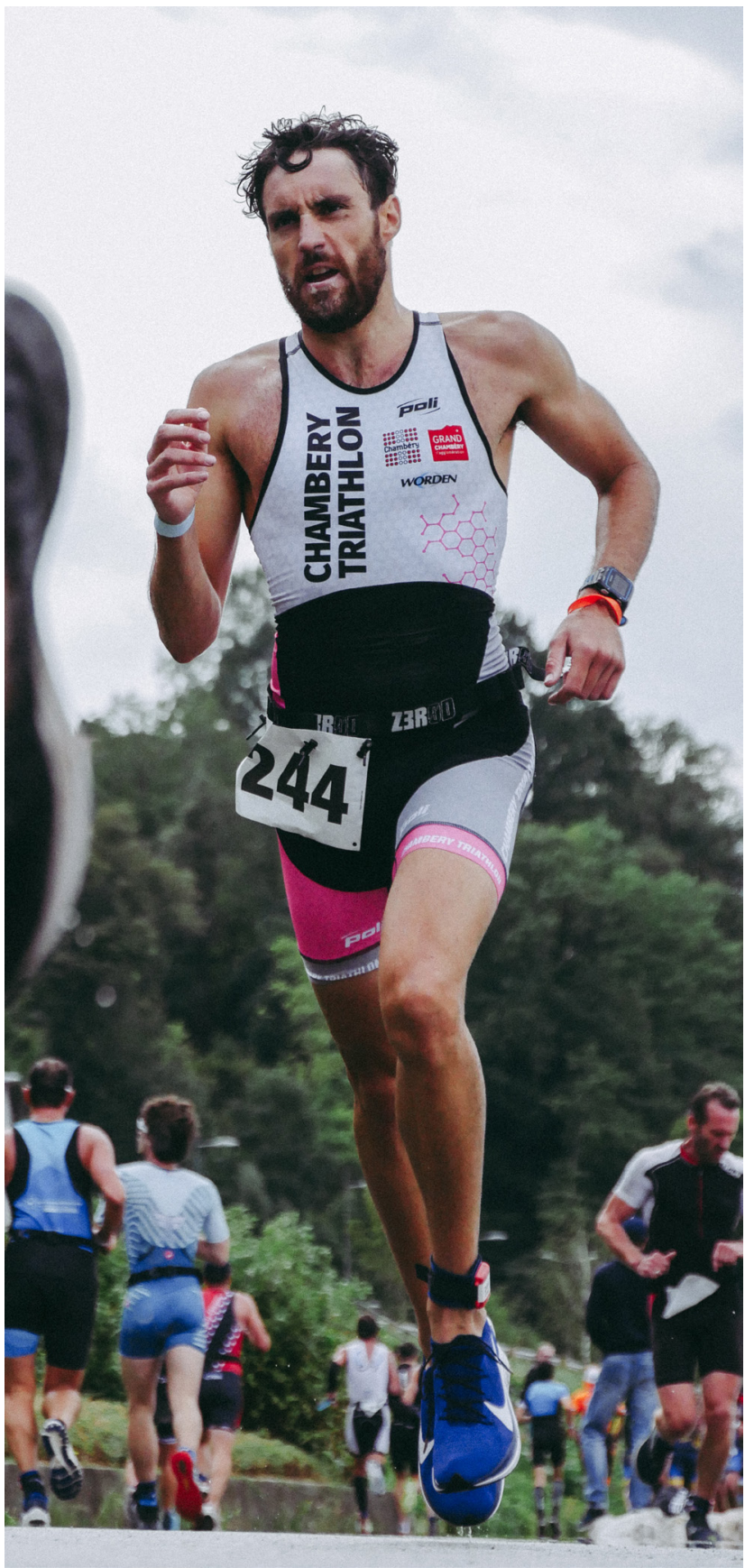

Figure 1 Johan Rodriguez on 8 September 2019 during the Aix-les-Bains Olympic distance triathlon. Olympic distance triathlon includes $1500 \mathrm{~m}$ of swimming, $40 \mathrm{~km}$ of cycling and $10 \mathrm{~km}$ of running. The photo was taken during the third discipline: running. 
quadriceps was a fine balance between promoting my muscular recovery and protecting my surgical sutures. During this first phase, I was fully aware of this and researched online about similar injuries but was unable to find this rare combination of injuries that I had. The advantage of this literature gap was that it allowed me to hope that my recovery could be unique. I was very determined and invested everything, clinging to every small positive step forward.

\section{After knee surgery, the blues}

I had my last operation on 4 August 2020, which was the multiligament reconstruction of the lateral collateral ligament and the popliteal tendon. The operation went very well, but for me, it was a complicated time. Because I was undergoing a second general anaesthesia within 3 months, I felt completely exhausted. Secondly, I saw this postoperative period as a barrier to my progress and not as a stage of my healing.

On 17 September 2020, I was finally allowed to full weight bear. It was a mixture of relief and sadness. On one hand, I was returning to my normal life, while on the other, I realised how far I still had to go in order to become competitive again.

\section{RETURN TO PHYSICAL ACTIVITIES}

In November 2020, I was able to swim again. It was a relief to feel the glide of the water, to find sensations that had been forgotten for too long, and to be able to finally return to sport. My return to cycling was done through home training, with the initial aim of recovering the range of motion in my knee. Step by step, I was able to hit the road again.

This recovery brought about a shared feeling: the satisfaction of moving forward in my sport, but also the worry about the immense road ahead to reach my goal. With my return to running, the first strides were as pleasant as they were difficult. Among the three disciplines of triathlon, running is the one that puts the most stress on my joints. I not only have weak quadriceps, but all of the muscles in my right leg are weak too. It will take time and specific work for me to regain my dynamic running skills again.

\section{THE FUTURE: MY RETURN TO SPORT}

It is February 2021, as I write this, and my rehabilitation is not yet over. In a few months, however, I hope this will all be behind me. I will then be able to start training again, with the dearest wish to wear a competition bib. It remains a complex psychological time for me, constantly mixing positive feelings of satisfaction with negative feelings of anger. This experience has taught me a lot. The medical staff played an essential role in my rehabilitation, and they motivated me and were a huge part of my plan to return to a high level. What is fundamental in my opinion is the evolution of their care, which was full of empathy and kindness at the start, and now filled with respect and pride.

\section{Take-home points}

Reflecting on my experiences, I would like to highlight three points that could be of help for clinicians:

- After a major accident, trauma or injury, a sincere and realistic approach regarding the diagnosis and prognosis is something that I feel many patients will appreciate. This will allow the patient to understand the situation and to better engage in their treatment.
During the rehabilitation process, I appreciated having been listened to by healthcare professionals to help them to adapt their approach (both physically and especially mentally).

- In my opinion, a progressive and reasonable return to physical activity and then sports is necessary. This is in order to balance the motivation of athletes to move again versus the risk of aggravation or reinjury when returning to sports.

Acknowledgements The author would like to thank Thomas Neri, Gilles Bruyère, Cyril Servel, Jérémy Rochefolle, Le Clos Champirol and Pascal Edouard for their investment in his medical care. He also thanks Thomas Neri, Pascal Edouard and Sven Putnis for their help in writing this manuscript.

Collaborators Thomas Neri; Pascal Edouard.

Contributors Substantial contributions to the conception of the manuscript, drafting, writing and revising of the manuscript, and approval of the final version to be published.

Funding The authors have not declared a specific grant for this research from any funding agency in the public, commercial or not-for-profit sectors.

Competing interests None declared.

Patient consent for publication Not required.

Provenance and peer review Not commissioned; externally peer reviewed.

(C) Author(s) (or their employer(s)) 2021. No commercial re-use. See rights and permissions. Published by BMJ.

\section{Check for updates}

To cite Rodriguez J. Br J Sports Med 2021;55:1179-1180.

Accepted 7 April 2021

Published Online First 27 April 2021

Br J Sports Med 2021;55:1179-1180.

doi:10.1136/bjsports-2021-104137

\section{ORCID iD}

Johan Rodriguez http://orcid.org/0000-0003-23822093 